explore patients' ideas and expectations before consultations, perceptions of symptoms and illnesses, reasons for consulting the doctors, ideas and preferences about treatment, attitudes to drugs, previous experiences with doctors, and what patients expect consultations to achieve. Researchers could ask also whether doctors educate their patients by word or deed to expect prescriptions (or no prescriptions) and whether patients choose doctors whose prescribing habits they like. Careful questioning should disentangle patients' ideal expectations for prescriptions (what they hope for or want) from their actual expectations (what they think will really happen).

Secondly, a similar approach is needed to sort out what general practitioners think and do about prescribing. Perhaps some doctors justify their poor prescribing habits by blaming patients instead of recognising that they sometimes misuse prescribing-for example, to close a difficult consultation. Qualitative studies could investigate doctors' perceptions of patients' preferences for prescriptions, previous experience with and knowledge of individual patients, beliefs about drugs, sense of time and other pressures during consultations, clinical assessments of patients' conditions, expectations of consultations, and other factors influencing the decisions to prescribe. Linking the two kinds of approach on a case by case basis would verify the accuracy of doctors' perceptions.

Finally, we still need to know more about the process of clinical consultations: how and how often patients make their expectations known, how doctors assess patients' expectations, and how well the two parties communicate on this subject. One way of taking this further would be to show a videotape of the consultation separately to each party afterwards and to interview them about what they were thinking at each point (I Cromarty, unpublished findings).

If doctors' perceptions do not correspond with patients' preferences poor or inappropriate prescribing, wastage of drugs, and unsatisfactory doctor-patient relationships may result. Reassuringly, recent research on patients' ideas about drugs suggests that more patient centred practice would not necessarily lead to higher rates of prescribing. ${ }^{15}$

NICKY BRITTEN

Lecturer in medical sociology

Department of General Practice,

United Medical and Dental Schools of Guy's and St Thomas's Hospitals, London SE11 6SP

1 Audit Commission. A prescription for improvement: towards more rational prescribing in general practice. London: HMSO, 1994.

2 Bradley C. Learning to say "no": an exercise in learning to decline inappropriate prescription requests. Education for General Practice 1994;5:112-9.

3 Marinker M. The doctor's role in prescribing. $₹$ R Coll Gen Pract 1973;23(suppl 2):26-9.

4 Beardon PHG, McGilchrist MM, McKendrick AD, McDevitt DG, MacDonald TM. Primary non-compliance with prescribed medication in primary care. $B M \mathcal{F}$ 1993;307:846-8.

5 Hull FM, Marshall T. Sources of information about new drugs and attitudes towards drug prescribing: an international study of differences between primary care physicians. Fam Pract 1987;4:123-8.

6 Stimson GV. General practitioners' estimates of patient expectations, and other aspects of their work. Swansea: Medical Sociology Research Centre, University College of Swansea, 1975. (Occasional paper No 3.)

7 Webb S, Lloyd M. Prescribing and referral in general practice: a study of patients' expectations and doctors' actions. Brf Gen Pract 1994;44:165-9.

8 Hepler CD, Clyne KE, Donta ST. Rationales expressed by empiric antibiotic prescribers. $A m \mathfrak{g}$ Hepler CD, Clyne KE, Donta ST.
Hosp Pharm 1982;39:1647-55.

9 Segal R, Hepler CD. Prescribers' beliefs and values as predictors of drug choices. Am f Hosp Pharm 1982;39:1891-7.

10 Stephenson MJ, Henry N, Norman GR. Factors influencing antibiotic use in acute respiratory tract infections in family practice. Can Fam Physician 1988;34:2149-52.

11 Hadsall RS, Freeman RA, Norwood GJ. Factors related to the prescribing of selected psychotropic drugs by primary care physicians. Soc Sci Med 1982;16:1747-56.

12 Schwartz RK, Soumerai SB, Avorn J. Physician motivations for nonscientific drug prescribing. Soc Sci Med 1989;28:577-82.

13 Bradley CP. Uncomfortable prescribing decisions: a critical incident study. $B M 7$ 1992;304:294-6.

14 Virii A, Britten N. A study of the relationship between patients' attitudes and doctors' prescribing. Fam Pract 1991;8:314-9.

15 Britten N. Patients' ideas about medicines: a qualitative study in a general practice population. Brf Gen Pract 1994;44:465-8.

\title{
Evidence based medicine
}

\section{A new journal to help doctors identify the information they need}

Busy doctors have never had time to read all the journals in their disciplines. There are, for example, about 20 clinical journals in adult internal medicine that report studies of direct importance to clinical practice, and in 1992 these journals included over 6000 articles with abstracts: to keep up the dedicated doctor would need to read about 17 articles a day every day of the year. ${ }^{1}$ In earlier eras limitations in our understanding of human biology and the absence of powerful clinical research methods meant that major advances were published far less commonly than now. Consequently, clinicians' failure to keep up did not harm patients.

Not any more. Rapid advances in physics, chemistry, and molecular biology since the second world war have led to a huge increase in the possibilities for managing patients. Effective treatments have appeared often for the first time. In parallel with these scientific advances researchers have developed methods of applied research-epitomised by the randomised controlled trial-to identify which new ideas for diagnosis, treatment, and predicting outcome actually work. Many do not and may do more harm than good.

Doctors need to know about the studies that show whether new ideas work, but their volume has grown enormously. What's more, many are published in inaccessible places, are not published at all, or are seriously flawed. Most busy doctors lack the time or skill to track down and evaluate this evidence. Although the skills of searching for evidence and critically appraising it are being mastered by growing numbers of doctors, many cannot keep up. Consequently there is a widening chasm between what we ought to do and what we actually do.

Evidence based medicine ${ }^{23}$ - which is described at length by William Rosenberg and Anna Donald on $p 1122^{4}$ attempts to fill the chasm by helping doctors find the information that will ensure they can provide optimum management for their patients. In essence, evidence based medicine is rooted in five linked ideas: firstly, clinical decisions should be based on the best available scientific evidence; secondly, the clinical problem-rather than habits or protocols-should determine the type of evidence to be sought; thirdly, identifying the best evidence means using epidemiological and biostatistical ways of thinking; fourthly, conclusions derived from identifying and critically appraising evidence are useful only if put into action in managing patients or making health care decisions; and, finally, performance should be constantly evaluated. The practice of evidence based medicine seems to be able to halt the progressive deterioration in clinical performance that is otherwise routine ${ }^{5}$ and which continuing medical education cannot stop. ${ }^{6}$

In 1991 the American College of Physicians began a journal, ACP fournal Club, which aimed to provide doctors with the up to date information they need. ${ }^{7}$ The editorial team screens far more journals than the average doctor can ever hope to read and identifies research articles of potential clinical relevance. Next, the team scrutinises the research 
methods used in these studies and rejects those whose conclusions are likely to be invalid or inapplicable.

The selected articles are then described on one page, beginning with an abstract that is structured and rewrittenbecause many abstracts published in the original journals do not include essential information. ${ }^{8}$ Each abstract is accompanied by a commentary from an expert in the subject who integrates it with other evidence and draws out the messages for practice. The articles cover the prevention, cause, and course of disease; screening; diagnosis; treatment; and rehabilitation; there are also studies of the economic aspects and quality of care and of strategies for improving the education and performance of doctors.

The results of this process are dramatic and cheering. The 6000 original articles on internal medicine published each year in general journals are distilled to 300 , and each article is on one page rather than four or five. Thus, even a doctor with a broadly based clinical practice can keep up with the latest important advances in clinical research by reading a page a day, and still have days to spare.

Not surprisingly ACP fournal Club has a high readership and is found extremely useful by its readers. Now the American College of Physicians and the BMJ Publishing Group are to collaborate to publish Evidence Based Medicine, a development of $A C P$ fournal Club. This will include some abstracts and commentaries published in ACP fournal Club but will also include new ones. These will come from the subspecialties of general medicine and from general practice, paediatrics, surgery, obstetrics and gynaecology, psychiatry, public health, and the parts of anaesthetics-for instance, the management of pain - that are common to much of medicine. Preference will be given to studies that cover conditions-like diabetes and depression-that are common and encountered in all specialties. Evidence Based Medicine will also publish systematic reviews of the effects of health care from the Cochrane Collaboration, selected reports from the York Centre for Reviews and Dissemination, educational material describing how to practise evidence based medicine, and editorials of general interest. Full information on subscribing to the new journal, which will be launched in October 1995, is available in the advertisement in this week's $B M Y$. *

ACP fournal Club and Evidence Based Medicine will publish the gold that intellectually intense processes will mine from the ore of about 100 of the world's top journals. Doctors owe it to themselves and their patients to make sure that they keep up with what is new and important.

*Opposite p 1137 in General Practice edition; on outside back cover of classified supplement in Clinical Research edition; and on inside front cover of International edition.

FRANK DAVIDOFF Editor, Annals of Internal Medicine

Philadelphia, PA 19106-1572,

USA

BRIAN HAYNES,

Editor, Evidence Based Medicine and ACP fournal Club Department of Clinical Epidemiology and Biostatistics,

McMaster University,

Hamilton,

Ontario

DAVE SACKETT,

Centre for Evidence Based Medicine,

John Radcliffe Hospital,

Oxford OX3 9DU

Editor, Evidence Based Medicine

London WC1H 9JR

1 Haynes RB. Where's the meat in clinical journals? ACP fournal Club 1993;119:A23-4

2 Evidence-based Medicine Working Group. Evidence-based medicine. A new approach to the teaching of medicine. IAMA 1992;268:2420-5.

3 Sackett DL, Haynes RB, Guyatt GH, Tugwell P. Clinical epidemiology: a basic science for clinical medicine. 2nd ed. Boston: Little, Brown, 1991.

4 Rosenberg W, Donald A. Evidence based medicine: an approach to clinical problem solving. BMf 1995;310:1122-6.

Shin $\mathrm{JH}$, Haynes RB, Johnston ME. Effect of problem-based, self-directed undergraduate education on life-long learning. Can Med Assoc f 1993;148:969-76.

6 Davis DA, Thompson MA, Oxman AD, Haynes RB. Evidence for effectiveness of CME: a review of 50 randomised controlled trials. $尹 A M A$ 1992;268:1111-7.

7 Haynes RB. The origins and aspirations of ACP fournal Club. ACP fournal Club 1991:January/ February:A18.

8 Ad Hoc Working Group for Critical Appraisal of the Medical Literature. A proposal for more informative abstracts of clinical articles. Ann Intern Med 1987;106:598-604.

\section{Fillers}

\section{Share an experience or lesson with $115000 \mathrm{BMJ}$ readers}

The journal's pages are at a premium, as those who have followed the recent discussion about obituaries will know. We therefore try to make the best of every part of each page. There are, however, an average of two or three spaces in each issue that are too small to use for regular contents because they are too near the foot of the page for a new article or section to start. We use them instead for "fillers."

Fillers have long included nuggets from the journal "One hundred years ago" and answers to "Any questions." Finding two years ago that there were more small spaces to fill than these items required and that we wanted more variety, we asked our authors and readers if they would like to help. We suggested pieces of up to 600 words on such topics as "A paper that changed my practice," "A patient who changed my practice," and "A memorable patient." The response was bounteous; since then we have received more than 300 pieces and published nearly half of them. We soon found that we did not need to go on printing an invitation-the fillers flowed in without it. Equally gratifyingly, our readers have been as keen to read these pieces as to write them, and we have had many appreciative comments.

Successful fillers are short and self contained and convey instruction, pathos, humour, or fun in simple language without technicality or unnecessary ornament. Six hundred words are the absolute maximum, but much shorter items are just as useful. The categories we originally suggested have been fruitful, though we have received disappointingly few accounts of "A paper that changed my practice"- a chastening reminder to editors that perhaps papers rarely do change practice. We would welcome more of these, as well as pieces on "The person who most influenced me" and "My most informative mistake." Our list of headings is not exclusive: originality and interest are the essentials, and some of the most enjoyable fillers have been unclassifiable.

Remember that pieces referring to particular patients require that person's or the relatives' permission and that because fillers are used when there is space to be filled our usual targets for publication time do not apply. We look forward to hearing more from you and thank you for the enjoyment your contributions have already given to us as well as to our readers.

ROGER ROBINSON

Associate editor

$B M F$

London WC1H 9JR 